\title{
Temperature, selective mortality and early growth in the short-lived clupeid Spratelloides gracilis
}

Eric D. H. Durieux ${ }^{1}$, Mark G. Meekan ${ }^{2}$, Dominique Ponton ${ }^{1}$, Laurent Vigliola ${ }^{3,{ }^{,}}$

\author{
${ }^{1}$ IRD, UR128, BP A5, 98848 Nouméa Cedex, Nouvelle Calédonie \\ ${ }^{2}$ Australian Institute of Marine Science, P.O. Box 40197, Casuarina MC, Darwin, Northern Territory \\ 0811, Australia \\ ${ }^{3}$ IRD, UR070, BP 70, 29280 Plouzané, France \\ *: Corresponding author : L. Vigliola, email address : laurent.vigliola@ird.fr
}

\begin{abstract}
:
Six cohorts of the silver-stripe round herring Spratelloides gracilis, a fast-growing and short-lived tropical clupeid, were collected as juveniles and then as adults during austral summers from November to February in 1998-1999 and 1999-2000, using light traps in the Dampier Archipelago, Western Australia. Otolith analysis allowed backcalculation of size and growth rate at age to examine the relative influences of selective mortality and water temperature on early growth. Negative sizeselective mortality and growth-selective mortality between the juvenile and the adult stages was found only in the cohort that was the smallest and slowest growing in the period immediately following hatching. Selective mortality preferentially removed members of this cohort that were smaller from age 0 to 15 days, and slower growing from 0 to 10 days, resulting in an elevation of size at age to, or even above, that of cohorts that had not undergone this process. Size and growth rate at 5 day age intervals in the first 20 days after hatching differed among cohorts within and between summers and were strongly and positively correlated $\left(r^{2}=0.61-0.83\right)$ with water temperature.
\end{abstract}

Keywords: environmental factors $\bullet$ Indo-Pacific region $\bullet$ life-history traits $\bullet$ otolith $\bullet$ pelagic fishes $\bullet$ size 
Changes in rates of survivorship during larval and juvenile stages are thought to be the principal cause of the variable nature of recruitment in stocks of marine fishes (Houde 1987; Cushing 1990; Leggett \& Deblois 1994). Early mortality is in turn strongly dependent on the growth rate of individuals so that fast growing cohorts often have higher rates of survivorship and consequently contribute disproportionately to the abundance of juvenile and adult life history stages (Bailey \& Houde 1989). on larval and juvenile growth of temperate marine fishes (Houde, 1989; Blaxter, 1991; Heath 1992). Tropical fishes are typically subjected to water temperatures above $20^{\circ} \mathrm{C}$ with low seasonal variation and they generally have high growth rates (Pauly, 1998). For this reason, it has been suggested that food, rather than temperature is the major factor in determining early growth of tropical fish (Houde 1989). However, relatively few studies have attempted to verify this hypothesis, particularly for multiple cohorts

60 (Thorrold \& Williams 1989; Milton et al. 1993; Wang \& Tzeng 1999; Meekan et al. 2003). This reflects the difficulty of capturing representative collections of the same cohort of fish when life history stages can occupy different habitats, each requiring specialized sampling gear (Meekan et al. 2006).

The relationship between growth rates and the larval environment is often confounded by the selective nature of mortality in the plankton. Bigger and/or fast66 growing larvae and juveniles tend to have higher survivorship than smaller and/or slowgrowing individuals (Anderson 1988; Miller et al. 1988; Bailey \& Houde 1989). Any comparison of the growth rates of cohorts and environmental factors is thus difficult if 
to determine the influence of the environment on cohort growth and survivorship, the

71 effects of size-selective mortality must be disentangled from those of environmental factors (Sinclair et al. 2002).

The tropical sprat, Spratelloides gracilis (Themminck \& Schlegel 1846), provides an ideal model for examining the relative effects of environmental factors and selective mortality on growth rate of cohorts. This species is pelagic throughout its life history but resides in nearshore waters around coral reefs where light traps can collect the late stage larvae, the juveniles and the adults abundantly (Meekan et al. 2001) and with equal efficiency (Meekan et al. 2000). It grows extremely fast, and has a very short life span of less than four months (Milton et al. 1991). Maturity is attained from $35 \mathrm{~mm}$ standard length (Milton \& Blaber 1991) to $45 \mathrm{~mm}$ fork length (Dalzell 1985) and spawning occurs throughout the year. S. gracilis has clear and interpretable otoliths for which daily deposition of increments has been validated (Milton et al. 1990). It has been demonstrated that this species can undergo size-selective mortality between larval and juvenile stages (Meekan et al. 2006). All these biological characteristics mean that the growth of several cohorts experiencing different environments can be analysed from samples collected over few months.

Here, we use otolith analysis to describe daily patterns in the growth of six cohorts of S. gracilis from hatching to adulthood. Specifically, growth trajectories of adults ( $\sim 60$ days old) and juveniles ( $\sim 30$ days old) of the same cohorts were back90 calculated from otoliths and compared during the first 20 days of life in order to 91 determine: i) the influence of larval growth traits on juvenile survivorship; ii) the extent of size/growth selective mortality between juvenile and adult stage in this species and iii) the relative influences of water temperature and size/growth-selective mortality in

94 determining the early growth patterns of the cohort. 
MATERIALS AND METHODS

97

\section{Collection techniques}

Light traps (Doherty 1987; see Fig. 1 in Meekan et al. 2001 for design) were

100 deployed in the Dampier Archipelago, Western Australia, from November 1998 to

101 February 1999 and from November 1999 to February 2000. Traps were set at five different stations, but only samples collected at Rosemary Island (Fig. 1A) were used in this study as these collected approximately $90 \%$ of catches of S. gracilis. Sampling

104 occurred during eleven nights centred on the new moon of each month except in

105 December 1999 when a cyclone warning reduced sampling effort to only 9 nights

106 (Table I). At each station, two traps were moored so that their entrance slits were 107 approximately one meter below the surface. Traps were deployed on the same moorings 108 each month and a timer and switch system ensured that they operated for the same 109 number of hours each night. Only five traps could be deployed or removed on the same 110 day so that two days were required to deploy or remove the 10 traps (2 traps per station

111 at five stations). Thus, only one trap per station was deployed on the first and last night

112 of each monthly trip while two traps collected fish at each station for the remaining nine

113 nights of each month. Overall, sampling effort resulted in 20 light trap catches for all

114 but one month. Although effort was reduced to 9 nights, a larger research vessel 115 allowed deploying and removing all traps at once so that 18 light trap catches were 116 available in December 1999 (Table I). Every morning, fish caught by each trap were 117 removed and immediately preserved in $70 \%$ ethanol.

118 Light traps collected a total of 56997 S. gracilis. As this collection was very 119 large, it was necessary to select a representative subsample of fish for otolith analysis. 
120 This was achieved by measuring the standard lengths (SL) of up to 60 fish that were

121 randomly selected from each daily catch (4 788 individuals in the subsample). These

122 measurements revealed bimodal size distributions in most months, with a first peak in

123 abundance at around $28 \mathrm{~mm} \mathrm{SL}$ and a second peak at $45 \mathrm{~mm}$ SL (Fig. 2). Patterns of

124 pigmentation and presence of eggs in thousands of individuals indicated that fish in the

$1251^{\text {st }}$ and $2^{\text {nd }}$ peaks were unambiguously composed of juveniles (with less pigment and no 126 eggs) and adults (a clearly defined silvery stripe and the frequent presence of eggs)

127 respectively. A total of 50 juveniles and 50 adults were then selected from each monthly

128 collection in proportion to their abundance in $1 \mathrm{~mm}$ size classes of SL within an

129 approximately $15 \mathrm{~mm}$ size range centred on each peak. As the size ranges sampled

130 around each peak were broad in order to include the full range of growth rates for each

131 cohort, subsequent age estimation revealed individuals from a wide range of hatch

132 dates. Some individuals were removed so that our analyses only compared individuals

133 in the cohort that had hatched within an approximately $20 \mathrm{~d}$ window and thus were

134 likely to have developed under similar environmental conditions. This resulted in a

135 reduction of total sample size for analysis from 583 to 417 adult and juvenile fish of

136 three cohorts (November, December, January) in each of two austral summers

137 (1998/1999; 1999/2000) (Table II). Cohorts were labelled by the month during which

138 juveniles were first sampled, so that adults of the same cohort were sampled the

139 following month. For example, the November 1998 cohort (coded 98Nov) consisted of

140 juveniles sampled in November and adults sampled in December.

142 Otolith analysis

143 Both sagittae were extracted from each of the selected fish and cleaned of 144 adhering tissue. One sagitta was mounted over the edge of a glass slide using 
145 thermoplastic glue and then oriented internal face up, rostrum outside the glass and the

146 core inside the edge of the glass. The protruding portion was ground off using lapping

147 film (9, 3 and $1 \mu \mathrm{m}$ grades). The otolith was then mounted on a new glass slide so that it

148 sat upright on its cut edge, in the centre of the slide. The upright portion was then

149 ground on the same series of lapping films to produce a thin transverse section that

150 contained the core. Sections were viewed with a microscope at 1000x magnification using an immersion oil objective and photographed using a Sony XC-77CE high resolution CCD camera. The public domain ImageJ program developed at the U.S. National Institute of Health (NIH) available at http://rsb.info.nih.gov/ij/ was used to

154 measure the distance of each daily increment to the core along the longest axis of the

155 otolith for each fish. Daily increment deposition has been validated for S. gracilis by

156 Milton et al. (1990) and we assumed that the first increment closest to the core of the 157 otolith was formed at the time of hatching (Campana \& Neilson 1985; Wellington \& 158 Victor 1989). Age determination error of less than a day was obtained from the repeated 159 analysis (2 readings per otolith) of a subsample of 40 randomly selected fish (20 160 juveniles and 20 adults). Given the relatively precise nature of age estimates, all otoliths 161 were analysed once by the same observer (ED).

162 Back-calculation of size from otoliths assumes proportionality between otolith 163 and somatic relative growth rates (Vigliola et al. 2000). The assumption was verified by 164 calculating a highly significant and strong $\left(r^{2}=0.88, P<0.001, n=583\right)$ allometric $(\mathrm{c}=$ 165 1.193, t-test, $P<0.001, n=583$ ) relationship between these variables for fish ranging 166 from 21 to $55 \mathrm{~mm}$ SL. Given this relationship between otolith and body size in $S$. 167 gracilis, we followed Vigliola et al. (2000) and used the modified Fry back-calculation model. This model included a biological intercept, corresponding to the fish size $\left(L_{\mathrm{op}}\right)$ 169 and the otolith radius $\left(R_{\mathrm{op}}\right)$ at hatching (age 0$)$. It was assumed that $L_{\mathrm{op}}$ was $4.4 \mathrm{~mm} \mathrm{SL}$ 
170 (Leis \& Carson-Ewart 2000) and for $R_{\mathrm{op}}$ we used the mean of the radius at age 0 day

$171 \quad\left(R_{\mathrm{o}}\right)$ of all individuals $\left(R_{\mathrm{op}}=9.957 \mu \mathrm{m} ; n=583\right)$.

\section{Data analyses}

174 We compared size and growth rates at age of juveniles and adults of the same

175 cohort in order to detect any size- and/or growth-selective mortality using repeated 176 measures (RM) MANOVAs (Chambers \& Miller 1995). Once this was done, size and

177 growth data back-calculated from juvenile and adults were pooled where no size/growth

178 selective mortality was detected and compared among cohorts using RM MANOVAs.

179 Since the youngest individual analysed was collected $20 \mathrm{~d}$ after hatching, back-

180 calculated standard lengths at age 0 (hatching), 5, 10, 15 and $20 \mathrm{~d}$ and back-calculated 181 growth rates at $0-5,5-10,10-15$ and $15-20 \mathrm{~d}$ age intervals were used, respectively, as 182 repeated measures in these analyses; then a contrast analysis was performed at each age 183 (for size) and age intervals (for growth rates). Growth rates for a given age interval were 184 calculated for each individual as the increase in fish size divided by the increase in fish 185 age over that interval for that individual (i.e. Growth $=\Delta \mathrm{L} / \Delta \mathrm{t}$ ). Following this, 186 individual size and growth rate at $5 \mathrm{~d}$ age intervals were averaged for fish of the same 187 cohorts and mean size/growth values correlated with mean monthly sea surface 188 temperature (SST) during the month of hatching using simple linear Pearson 189 correlation. All statistical analyses used Statistica software (Statsoft). Monthly SST data 190 for the Dampier Archipelago was derived from satellite remote sensing for one degree 191 latitude by one degree longitude boxes (IGOSS-NMC products). 
Between October and February, SSTs increased from 25.5 to $30-31^{\circ} \mathrm{C}$ (Fig. 1B).

197 Mean monthly SSTs were higher in the summer of 1998/1999 than summer of $1999 / 2000$, with the greatest difference of $1.2^{\circ} \mathrm{C}$ between summers occurring in 199 January.

\section{Light trap catches}

A total of 56997 S. gracilis ranging in size from 17 to $57 \mathrm{~mm}$ SL were collected during the 1998/1999 and 1999/2000 austral summers with most fish collected in

204 December in both years (Table I). Catches were higher throughout the warmer $2051998 / 1999$ summer than the cooler 1999/2000 summer, with a total of 42899 fish 206 collected between November 1998 and February 1999, while only 14098 individuals 207 were collected during the same period in the following year (Table I). Abundance of 208 fish smaller than $37 \mathrm{~mm}$ (i.e. juveniles) followed the same patterns as total catch with 209 greater numbers per trap in 1998/1999 summer and in December of each summer (Table 210 I).

\section{Population growth trajectory}

213 The growth of S. gracilis in the Dampier Archipelago was extremely rapid (Fig.

2143 ). Fish from cohorts that were sampled for the first time by light traps were juveniles

215 that had been spawned approximately one month prior to capture (Table II). When the 216 cohort was then re-sampled a month later these fish had already become adults at a 217 relatively small size of $40-50 \mathrm{~mm}$ SL. Despite large differences in size and age at 218 capture, both juvenile and adult samples encompassed the full range of growth 
219 trajectories with fish sampled from lower to upper limits of the population growth 220 envelope (Fig. 3).

\section{Selective mortality}

Growth trajectories of juvenile fish collected in December 1998, January,

November, December 1999 and January 2000 did not differ from that of adults from the same cohorts (Table III), implying no detectable size/growth-selective mortality for these 5 cohorts. In contrast, back-calculated size-at-age and growth rates of fish collected as juveniles in November 1998 were significantly different from that obtained from fish of the same cohort collected as adults in December 1998 (Table III). Contrast analysis revealed that adults of this November 98 cohort had significantly larger size at age $0,5,10$, and $15 \mathrm{~d}$, and higher growth rate for $0-5$ and 5-10 d age intervals than juveniles of the same cohort. Therefore, those fish that survived to become adults in December 1998 were bigger at hatching and grew significantly faster at younger ages than the juveniles of the same cohort collected in November 1998 (Fig. 4). This implies

234 that size/growth-selective mortality occurred sometime during the transition of these

235 fish between juvenile and adult stages.

\section{Comparison of growth patterns among cohorts and summers}

Adult and juvenile samples were pooled for each cohort (with the exception of

239 the November 1998 cohort where size/growth-selective mortality occurred) and 240 analysed using RM MANOVAs. This detected highly significant differences in both 241 size-at-age (factor Age $\mathrm{x}$ pooled sample, multivariate Wilk's $\lambda=0.544, \mathrm{~F}_{24,1421}=$ $24211.282, P<0.001$ ) and growth rate (factor Age x pooled sample, multivariate Wilk's $\lambda$ $\left.243=0.754, \mathrm{~F}_{18,1154}=6.720, P<0.001\right)$ among cohorts (Fig. 5). For any given month, size- 
at-age was typically larger and growth rate faster during the warmer summer of

245 1998/1999 than the colder summer of 1999/2000 (Fig. 5). Smallest sizes / slowest

246 growth rates were recorded during the month of November when water temperatures

247 were relatively cool. Size-at-age and growth rate increased with temperatures during

248 December and January (Fig. 5, Fig. 1B). The juveniles caught in November 98 were

249 significantly smaller and slower-growing at all ages younger than 10d than any other

250 cohort. From 10 to $20 \mathrm{~d}$ after hatching, these juveniles grew faster so that at $20 \mathrm{~d}$ after

251 hatching, individuals caught in November 1999 were significantly smaller than the

252 juveniles caught in November 1998. Strong $\left(r^{2}=0.61-0.83\right)$, positive and significant

253 correlations were found between water temperature and fish size at all ages, except at

254 hatching (Fig. 6). Likewise, strong $\left(r^{2}=0.66-0.78\right)$, positive and significant correlations were found between water temperature and fish growth rate at 0-5, 5-10, 10-15d and 0-20d but not at the 15-20d age interval (Fig. 6).

\section{DISCUSSION}

S. gracilis is a very fast growing and short lived clupeid fish. At our study site in the Dampier Archipelago, Western Australia, S. gracilis grew at the upper margin of its known range in growth rate, with mean instantaneous rate at $20 \mathrm{~d}$ after hatching attaining $0.91 \mathrm{~mm} . \mathrm{d}^{-1}$, so that individuals of $45 \mathrm{~mm} \mathrm{SL} \mathrm{(i.e.} \mathrm{adult} \mathrm{size)} \mathrm{were} \mathrm{only}$

264 around $60 \mathrm{~d}$ of age. The oldest fish collected in our study attained an age of only $99 \mathrm{~d}$.

265 These growth rates compare with a low for the species of $0.37 \mathrm{~mm} . \mathrm{d}^{-1}$ recorded in the 266 Solomon Islands and a high of $1.19 \mathrm{~mm} \cdot \mathrm{d}^{-1}$ at $30 \mathrm{~d}$ after hatching at Lizard Island, Great

267 Barrier Reef, Australia (Milton et al. 1991). 
Size and growth-selective mortality was detected between the juvenile and adult stages only in the cohort of fish collected as juveniles in November and adults in

271 December 1998 (Fig. 4). Selective mortality preferentially removed fish that were smaller / slower-growing in the period immediately following hatching, so that size-atage of the adult cohort was close to or the same as that of cohorts captured as juveniles in December and January of that summer (Fig. 5). This cohort was smallest at hatching and grew slowest during early life history (the juveniles captured in November 1998, Fig. 4 and 5), consistent with the predictions of the growth-mortality hypothesis (Anderson 1988; Miller et al. 1988; Houde 1989). Similarly, field studies of other temperate and tropical species have also found selective mortality to act on slower growing cohorts (e.g. Meekan \& Fortier 1996; Takasuka et al. 2003; Raventos \& Macpherson 2005; Vigliola et al. 2007).

Selective mortality was not detected in the cohort of fish first collected in November 1999, despite this cohort growing slowly and having a relatively small size at age at 20d after hatching (Fig. 5). This implies that growth rates and size at age during the earliest part of the life history are more important as determinants of the occurrence of selective mortality than at older ages, a finding again consistent with the growthmortality hypothesis. Selective mortality resulted in the adults collected in December 1998 having average sizes at hatching that were larger than those of any other cohort (Fig. 5). Prior to the action of selection, the population of juveniles from which these survivors originated had the smallest size at hatching of any cohort. There was also an increase in variability in mean hatching size, probably reflecting the relatively small sample size of adults. Differences in size at hatching among individuals in the cohort were propagated by growth during early larval life and provided the traits on which 
selection acted later in the life history. Changes in the trait of size at hatching show the

295 importance of parental contributions to the outcome of selective events operating on 296 later stages, consistent with the findings of studies on this (Meekan et al. 2006) and 297 other species (Marteinsdottir \& Steinarsson 1998; Vigliola \& Meekan 2002; Berkeley et 298 al 2004; Vigliola et al. 2007).

We found size/growth-selective mortality occurring between the juvenile and 301 adult life history stages in only one of six cohorts of $S$. gracilis.. These findings suggest that survivorship during the juvenile stage in this species is mostly independent of growth and size-selective mortality. However, this does not mean that both mechanisms are not occurring during the larval stage of this species. Meekan et al. (2006) detected size-selective mortality during the transition of $S$. gracilis from larvae to juveniles at Ningaloo reef, $600 \mathrm{~km}$ south of the Dampier Archipelago. Here, we were unable to sample larvae, as the smallest fish that recruited to our sampling gear (light traps) were already juveniles. As the importance of size-selective processes will decline as fish

309 grow, due to the reduction in the number of predators to which they are susceptible

310 (Bailey \& Houde 1989), selective mortality is likely to have occurred earlier in the life 311 history. Our study shows that growth and size selective mortality on earlier stages 312 would have had relatively little influence on the strong correlation between size/growth

313 at age of $S$. gracilis and water temperature from $0-20 \mathrm{~d}$ after hatching. Indeed, the effect

314 of this selective mortality would be to raise average growth rates for the cohort, in turn

315 decreasing the strength of correlations between water temperature and growth rate by 316 reducing the variation in growth present in the data set. This assumes that selective 317 mortality acts in a consistent direction in all cohorts, by always removing the smallest, 318 slowest-growing individuals, as generally appears to be the case under natural selection 
319 (e.g. Hovenkamp 1992; Sogard 1997; Hare \& Cowen 1997; Shima \& Findlay 2002;

320 Raventos \& Macpherson 2005; Vigliola \& Meekan 2002; Folkvord 2005).

Size/growth at age from 0-20d after hatching of S. gracilis were very strongly correlated with temperature $\left(\mathrm{r}^{2}\right.$ values ranging from $0.61-0.83$, Fig. 6). Relationships of

324 this strength are unusual; relatively few studies have found that water temperatures could explain more than $30 \%$ of the variance in larval growth (McCormick \& Molony 1995; Meekan et al. 2003), and most have recorded weaker correlations (Searcy \& Sponaugle 2000; Wilson \& Meekan 2001, 2002; Bergenius et al. 2005). One obvious reason that these correlations were relatively robust might be that most cohorts underwent little size/growth-selective mortality. We have shown that this process would

330 be likely to weaken any correlation between environmental factors and growth rates, and this may have confounded earlier studies (Sinclair et al. 2002). However, we do not know to what degree our correlations reflected the relative contributions of temperature and food to growth, as we did not measure food availability for S. gracilis. In the

334 tropics, it has been argued that due to relatively fast growth rates and thus high rates of

335 food intake required by fish in larval stages, food supply should be the primary determinant of growth rate variability (Houde 1989). In our study the strength of the correlations between size/growth at age during the first $20 \mathrm{~d}$ after hatching and temperature imply that even in this very fast growing species, growth rates are unlikely to be solely determined by food availability. This idea is supported by field evidence

340 that shows that temperature rather than food might be an important determinant of 341 growth rates of the larvae of tropical reef fishes (Meekan et al. 2003). Interestingly,

342 water temperature was not correlated with size at hatching of S. gracilis. This suggests

343 that the effect of parental identity and provisioning on size at hatching over-rides that of 
344 the physical environment in which the eggs develop (Marteinsdottir \& Steinarsson 1998; McCormick 2003).

During the warmer 1998-99 summer we collected almost 3 times the number of

S. gracilis than in the cooler summer of 1999-2000. As growth was positively correlated with sea surface temperature, growth rates of $S$. gracilis were also higher on any given month of $1998 / 99$ than $1999 / 2000$. Our data were too limited to infer whether faster growth during the warmer summer was merely coincidental, or reflected a causal phenomenon. However, a positive correlation between growth rates and abundance on an inter-annual basis is consistent with both temperate and tropical studies of growth rate during the early life history of marine fishes (e.g. Meekan \& Fortier 1996;

355 Campana 1996; Meekan et al. 2003; Jenkins \& King 2006). At monthly intervals the correlation between growth rate and catches broke down, so that catches increased in both summers from November to December with warming surface waters, but declined in the warmest months of January and February (Table I). This contrasts with a number of studies that have found strong relationships between monthly growth rates and cohort

360 size (Bergenius et al. 2002; Shima \& Findlay 2002; Wilson \& Meekan 2002). There are a number of possible explanations for this lack of correlation. Unlike other studies, we examined the abundance of the study species in both juvenile and adult stages and it is possible that factors other than growth also influence abundance of adults, such as

364 advection and non-selective predation.

In summary, despite the presence of selective mortality, larval growth rates of

367 cohorts of $S$. gracilis were strongly correlated with water temperature. The effect of 368 selective mortality between juvenile and adult stage was to raise the mean size at age 
369 during early growth to, or even above those of other faster growing cohorts that had not

370 undergone this process. On an inter-annual basis, faster growth might have a positive 371 influence on fish abundance, although this correlation broke down within a summer for

372 unknown reasons. Our study shows that it is possible to disentangle the relative

373 influences of environmental factors and selective mortality on the early growth of 374 cohorts of marine fishes.

375

376 ACKNOWLEDGMENTS

377

378 The Australian Institute of Marine Science and the Institut de Recherche pour le 379 Développement provided funding for this research. K Brooks, A Halford, S Trovato, G 380 Mou-Tham and numerous volunteers helped with both field and laboratory work. We 381 are grateful to the anonymous reviewers for comments on and corrections to the 382 manuscript. 
Anderson, J. T. (1988). A review of size dependent survival during pre-recruit stages of fishes in relation to recruitment. Journal of Northwest Atlantic Fisheries Science

Bailey, K. M., \& Houde, E. D. (1989). Predation on eggs and larvae of marine fishes 8, 55-66. and the recruitment problem. Advances in Marine Biology 25, 1-83.

Bergenius, M. A. J., Meekan, M. G., Robertson, D. R. \& McCormick M. I. (2002). Larval growth predicts the recruitment success of a coral reef fish. Oecologia 131, 521-525. doi:10.1007/s00442-002-0918-4.

Bergenius M. A. J., McCormick M. I., Meekan M. G. \& Robertson D. R. (2005). Environmental influences on larval duration, growth and magnitude of settlement of a coral reef fish. Marine Biology 147, 291-300. doi:10.1007/s00227-005-1575$\mathrm{Z}$.

Berkeley S. A., Chapman C. \& Sogard S. M. (2004). Maternal age as a determinant of larval growth and survival in a marine fish, Sebastes melanops. Ecology 85, 12581264.

400 Blaxter, J.H.S. (1991). The effect of temperature on larval fishes. Netherlands Journal 401 of Zoology 42, 336-357.

402 Campana S. E. (1996). Year-class strength and growth rate in young Atlantic cod Gadus morhua. Marine Ecology Progress Series 135, 21-26.

404 Campana S. E. \& Neilson J. D. (1985). Microstructure of fish otoliths. Canadian $405 \quad$ Journal of Fisheries and Aquatic Science 42, 1014-1032. 
406 Chambers R. C. \& Miller T. J. (1995). Evaluating growth by means of otolith increment analysis: spectral properties of individual-level longitudinal data. In Recent developments in fish otolith research. Edited by Secor D.H., Dean J.M., Campana S.E. (eds) University of South Carolina Press, Columbia, pp. 155-175.

Cushing D. H. (1990). Plankton production and year-class strength in fish populations: An update of the match/mismatch hypothesis. Advances in Marine Biology 26, 249-294.

Dalzell, P. (1985). Some aspects of the reproductive biology of Spratelloides gracilis (Schlegel) in the Ysabel Passage, Papua New Guinea. Journal of Fish Biology 27, 229-237.

Doherty P. J. (1987). Light traps: selective but useful devices for quantifying the distributions and abundances of larval fishes. Bulletin of Marine Science 41, 423431.

Folkvord A. (2005). Comparison of size-at-age of larval Atlantic cod (Gadus morhua) from different populations based on size- and temperature-dependent growth models. Canadian Journal of Fisheries and Aquatic Science 62, 1037-1052.

Hare J. A. \& Cowen R. K. (1997). Size, growth, development, and survival of the 424 planktonic larvae of Pomatomus saltatrix (Pisces: Pomatidae). Ecology 78, 2415-

Heath, M.R. (1992). Field investigations of the early life stages of marine fish. Advances in Marine Biology 28, 1-174. Fisheries Society Symposium 2, 17-29. 
430 Houde E. D. (1989). Comparative growth mortality, and energetics of marine fish 431 larvae: temperature and implied latitudinal effects. Fishery Bulletin 87, 471-495.

432 Hovenkamp F. (1992). Growth-dependent mortality of larval plaice Pleuronectes 433 platessa in the North Sea. Marine Ecology Progress Series 82, 95-101.

434 Jenkins G. P. \& King D. (2006). Variation in larval growth can predict the recruitment of a temperate, seagrass-associated fish. Oecologia 147, 641-649. doi:10.1007/s00442-005-0336-5.

Leggett W. C. \& Deblois E. (1994). Recruitment in marine fishes: is it regulated by starvation and predation in egg and larval stages ? Netherlands Journal of Sea Research 32, 119-134.

Leis J. M. \& Carson-Ewart B. M. (2000). The larvae of Indo-Pacific coastal fishes: an identification guide to marine fish larvae. Fauna Malesiana Handbooks 2, Brill.

Marteinsdottir G. \& Steinarsson A. (1998). Maternal influence on the size and viability of Iceland cod Gadus morhua eggs and larvae. Journal of Fish Biology 52, 12411258. doi:10.1111/j.1095-8649.1998.tb00969.x.

McCormick M. I. (2003). Consumption of coral propagules after mass spawning enhances larval quality of damselfish through maternal effects. Oecologia 136,

McCormick M. I. \& Molony B. W. (1995). Influence of water temperature during the larval stage on size, age and body condition of a tropical reef fish at settlement. Marine Ecology Progress Series 118, 59-68.

Meekan M. G. \& Fortier L. (1996). Selection for fast growth during the larval life of Atlantic cod Gadus morhua on the Scotian shelf. Marine Ecology Progress Series 137, 25-37. 
454 Meekan M. G., Doherty P. J. \& White L. Jr. (2000). Recapture experiments show the low sampling efficiency of light traps. Bulletin of Marine Science 67, 875-885.

Meekan M. G., Carleton J. H., McKinnon A. D., Flynn K. \& Furnas M. (2003). What determines the growth of tropical fish larvae in the plankton: food or temperature? Marine Ecology Progress Series 256, 193-204.

Meekan M. G., Wilson S. G., Halford A. \& Retzel A. (2001). A comparison of catches 460 of fishes and invertebrates by two light trap designs, in tropical NW Australia. Marine

Biology 139, 373-381. doi:10.1007/s002270100577.

Meekan M. G., Vigliola L., Hansen A., Doherty P. J., Halford A. \& Carleton J. H. 463 (2006). Size-selective mortality throughout the life history of a fast growing clupeid Spratelloides gracilis. Marine Ecology Progress Series 317, 237-244.

Miller T. J., Crowder L. B., Rice J. A. \& Marschall E. A. (1988). Larval size and recruitment mechanisms in fishes: toward a conceptual framework. Canadian Journal of Fisheries and Aquatic Science 45, 1657-1670.

Milton D. A., Blaber S. J. M. \& Rawlinson N. J. F. (1990). Age and growth of major 469 baitfish species in Solomon Islands and Maldives. In : Blaber SJM, Copland JW (eds) Tuna baitfish in the Indo-Pacific region. ACIAR Proc 30, 134-140.

Milton D. A. \& Blaber S. J. M. (1991). Maturation, spawning seasonnality, and proximate spawning stimuli of six species of tuna baitfish in the Solomons Islands. Fishery Bulletin 89, 221-237.

Milton D. A., Blaber S. J. M. \& Rawlinson N. J. F. (1991). Age and growth of three 475 species of tuna baitfish (genus: Spratelloides) in the tropical Indo-Pacific. Journal of Fish Biology 39, 849-866. doi:10.1111/j.1095-8649.1991.tb04414.x. 
Milton D. A., Blaber S. J. M. \& Rawlinson N. J. F. (1993). Age and growth of three species of Clupeids from Kiribati, tropical central south Pacific. Journal of Fish Biology 43, 89-108. doi:10.1111/j.1095-8649.1993.tb00413.x.

Nielsen R. \& Munk P. (2004). Growth pattern and growth dependent mortality of larval and pelagic juvenile north sea cod Gadus morhua. Marine Ecology Progress Series 278, 261-270.

Pauly, D. (1998). Tropical fishes: patterns and propensities. Journal of Fish Biology 53, 1-17. doi:10.1111/j.1095-8649.1998.tb01014.x.

Raventos N. \& Macpherson E. (2005). Effect of pelagic larval growth and size-athatching on post-settlement survivorship in two temperate labrid fish of the genus Symphodus. Marine Ecology Progress Series 285, 205-211.

Searcy S. P. \& Sponaugle S. (2000). Variable larval growth in a coral reef fish. Marine Ecology Progress Series 206, 213-226.

Shima J. S. \& Findlay A. M. (2002). Pelagic larval growth rate impacts benthic settlement and survival of a temperate reef fish. Marine Ecology Progress Series 235, 303-309.

Sinclair A. F., Swain D. P. \& Hanson J. M. (2002). Disentangling the effects of sizeselective mortality, density, and temperature on length-at-age. Canadian Journal of Fisheries and Aquatic Science 59, 372-382. doi:10.1139/F02-014.

Sogard S. M. (1997). Size-selective mortality in the juvenile stage of teleost fishes: a review. Bulletin of Marine Science 60, 1129-1157. larval Japanese anchovy Engraulis japonicus in Sagami Bay. Marine Ecology Progress Series 252, 223-238. 
Thorrold S. R. \& Williams D. McB. (1989). Analysis of otolith microstructure to determine growth histories in larval cohorts of tropical herring (Herklotsichthys castelnaui). Canadian Journal of Fisheries and Aquatic Science 46, 1615-1624.

Vigliola L. \& Meekan M. G. (2002). Size at hatching and planktonic growth determine post-settlement survivorship of a coral reef fish. Oecologia 131, 89-93. doi:10.1007/s00442-0001-0866-4.

Vigliola L., Harmelin-Vivien M. \& Meekan M. G. (2000). Comparison of techniques of back-calculation of growth and settlement marks from the otoliths of three species of Diplodus from the Mediterranean Sea. Canadian Journal of Fisheries and Aquatic Science 57, 1291-1299.

Vigliola L., Doherty P. J., Meekan M. G., Drown D., Jones M. E. \& Barber P. H. (2007) Genetic identity determines risk of post-settlement mortality of a coral reef fish. Ecology 88, 1263-1277

514 Wang Y. -T. and Tzeng W. -N. (1999). Differences in growth rates among cohorts of Encrasicholina punctifer and Engraulis japonicus larvae in the coastal waters off Tanshui River Estuary, Taiwan, as indicated by otolith microstructure analysis. Journal of Fish Biology 54, 1002-1016. doi:10.1111/j.1095-8649.1999.tb00853.x.

Wellington G. M. \& Victor B. C. (1989). Planktonic larval duration of one hundred species of Pacific and Atlantic damselfishes (Pomacentridae). Marine Biology 101, 557-567. doi:10.1007/BF00541659.

Wilson D. \& Meekan M. G. (2001). Environmental influences on patterns of larval supply of reef fishes. Marine Ecology Progress Series 222, 197-207.

523 Wilson D. \& Meekan M. G. (2002). Growth-related advantages for survival to the point

524 of replenishment in the coral reef fish Stegastes partitus (Pomacentritade). Marine

525 Ecology Progress Series 231, 247-260. 
527 Juvenile catch corresponds to the catch of individuals smaller than $37 \mathrm{~mm}$. Catches are given as number of fish ( $\mathrm{Nb}$ fish) and mean number of 528 fish per trap ( $\mathrm{Nb}$ fish/trap).

\begin{tabular}{lllllllll}
\hline Summer & Month & Trap in - out & Nb nights & Nb traps & Total catch & Juvenile catch \\
& & & & & Nb fish & Nb fish/trap & Nb fish & Nb fish/trap \\
\hline $1998 / 99$ & Nov-98 & $14-25$ Nov 1998 & 11 & 20 & 10568 & 528 & 9598 & 480 \\
& Dec-98 & $15-26$ Dec 1998 & 11 & 20 & 24110 & 1206 & 18081 & 904 \\
& Jan-99 & $13-24$ Jan 1999 & 11 & 20 & 2176 & 109 & 1190 & 60 \\
& Feb-99 & $11-22$ Feb 1999 & 11 & 20 & 6045 & 302 & 3655 & 183 \\
$1999 / 00$ & Nov-99 & $3-14$ Nov 1999 & 11 & 20 & 1701 & 85 & 1231 & 62 \\
& Dec-99 & $4-13$ Dec 1999 & $9 *$ & 18 & 10086 & 560 & 8226 & 457 \\
& Jan-00 & $4-15$ Jan 2000 & 11 & 20 & 919 & 46 & 134 & 7
\end{tabular}

529 * field work was shortened due to cyclone warning but a larger research vessel allowed deployment of 2 traps during the first and last night of 530 sampling, while only one trap could be deployed on the first and last night of other months. 
531 Table II. Hatch date window, mean age, and number $(n)$ of Spratelloides gracilis of 6

532 cohorts collected by light traps in summers 1998/1999 (coded 98Nov, 98Dec, and

533 99Jan) and 1999/2000 (coded 99Nov, 99Dec, 00Jan) at the juvenile and adult stages in

534 the Dampier Archipelago (Western Australia) and used in back-calculation analyses.

\begin{tabular}{|c|c|c|c|c|c|}
\hline \multirow[b]{2}{*}{ Summer } & \multirow[b]{2}{*}{ Cohort Hatch date window } & \multirow[b]{2}{*}{ Stage } & \multicolumn{3}{|c|}{ Mean age Size at capture } \\
\hline & & & $\pm \mathrm{sd}(\mathrm{d})$ & $\pm \mathrm{sd}(\mathrm{mm})$ & $n$ \\
\hline \multirow[t]{6}{*}{$1998 / 99$} & 98Nov $9-28$ Oct 1998 & Juvenile & $33 \pm 5$ & $27.4 \pm 2.8$ & 46 \\
\hline & & Adult & $60 \pm 7$ & $43.9 \pm 1.9$ & 24 \\
\hline & 98Dec 11 Nov - 5 Dec 1998 & Juvenile & $27 \pm 4$ & $26.5 \pm 2.5$ & 50 \\
\hline & & Adult & $63 \pm 7$ & $46.5 \pm 3.4$ & 22 \\
\hline & 99Jan 6-29 Dec 1998 & Juvenile & $32 \pm 6$ & $26.8 \pm 3.8$ & 35 \\
\hline & & Adult & $63 \pm 6$ & $43.8 \pm 3.3$ & 36 \\
\hline \multirow[t]{6}{*}{$1999 / 2000$} & 99Nov 24 Sept - 20 Oct 1999 & Juvenile & $37 \pm 6$ & $28.1 \pm 3.2$ & 42 \\
\hline & & Adult & $58 \pm 7$ & $45.3 \pm 2.6$ & 30 \\
\hline & 99Dec 6-17 Nov 1999 & Juvenile & $30 \pm 3$ & $27.5 \pm 3.1$ & 22 \\
\hline & & Adult & $56 \pm 3$ & $44.8 \pm 2.9$ & 23 \\
\hline & 00Jan 24 Nov - 12 Dec 1999 & Juvenile & $37 \pm 5$ & $29.8 \pm 4.0$ & 49 \\
\hline & & Adult & $65 \pm 6$ & $45.3 \pm 2.9$ & 38 \\
\hline
\end{tabular}


536 Table III. Summary of results of RM MANOVAs that compared back-calculated

537 standard lengths at $0,5,10,15$ and $20 \mathrm{~d}$ age (coded SL) and back-calculated growth

538 rates at 0-5, 5-10, 10-15 and 15-20 d age intervals (coded $\mathrm{G}$ ) between juvenile and adult

539 stages for 6 cohorts of Spratelloides gracilis collected in 1998/1999 (coded 98Nov,

540 98Dec, and 99Jan) and 1999/2000 (coded 99Nov, 99Dec, 00Jan). One RM MANOVA

541 was performed for each cohort and multivariate test for repeated measures reported

542 below for factor Age x Stage. df: degrees of freedom; F: value of $\mathrm{F}$ statistic; $P$ :

543 associated probability to Wilk's multivariate test.

\begin{tabular}{|c|c|c|c|c|c|c|}
\hline Summer & Cohort code & Variable code & $\mathrm{df}$ & Wilk's $\lambda$ & $\mathrm{F}$ & $P$ \\
\hline \multirow[t]{6}{*}{$1998 / 99$} & $98 \mathrm{Nov}$ & SL & 4,65 & 0.637 & 9.26 & $<0.001$ \\
\hline & & $\mathrm{G}$ & 3,66 & 0.803 & 5.39 & $<0.002$ \\
\hline & 98Dec & SL & 4,67 & 0.953 & 0.83 & 0.512 \\
\hline & & $\mathrm{G}$ & 3,68 & 0.972 & 0.65 & 0.586 \\
\hline & 99Jan & SL & 4,66 & 0.889 & 2.06 & 0.096 \\
\hline & & $\mathrm{G}$ & 3,67 & 0.926 & 1.79 & 0.157 \\
\hline \multirow[t]{6}{*}{$1999 / 2000$} & $99 \mathrm{Nov}$ & SL & 4,67 & 0.917 & 1.52 & 0.206 \\
\hline & & $\mathrm{G}$ & 3,68 & 0.950 & 1.18 & 0.320 \\
\hline & 99Dec & SL & 4,40 & 0.842 & 1.88 & 0.133 \\
\hline & & $\mathrm{G}$ & 3,41 & 0.842 & 2.56 & 0.067 \\
\hline & 00Jan & SL & 4,82 & 0.940 & 1.31 & 0.272 \\
\hline & & $\mathrm{G}$ & 3,83 & 0.950 & 1.44 & 0.235 \\
\hline
\end{tabular}

544

545 
547 Fig. 1. A. Map of Dampier Archipelago, Western Australia, with location of sampling sites where light traps were deployed (filled star shows site where most Spratelloides gracilis were collected). B. Mean monthly sea surface temperature (SST) of the area during the sampling periods (summers 1998/1999 and 1999/2000) were obtained from satellite remote sensing data.

Fig. 2. Monthly size frequency distributions of Spratelloides gracilis collected by light traps in summers 1998/1999 and 1999/2000 in the Dampier Archipelago, Western Australia. The dotted line indicates the limit in size between juvenile (fish smaller than $37 \mathrm{~mm}$ ) and adult (fish larger than $37 \mathrm{~mm}$ ). Cohorts were labelled by the month during which juveniles were first sampled, so that adults of the same cohort were sampled the following month. For example, the November 1998 cohort (coded 98Nov) consisted of juveniles sampled in November and adults sampled in December 1998.

Fig. 3. Back-calculated size-at-age data (dots) of Spratelloides gracilis collected by light traps in summers 1998/1999 and 1999/2000 in the Dampier Archipelago, Western Australia. Juvenile (circle) and adult (square) size-at-capture data are shown. $n=18988$ size-at-age records from 417 fish.

Fig. 4. Mean size-at-age (A) and mean growth rate (B) from hatching to 20d backcalculated from otoliths of juvenile (filled circles, $n=46$ ) and adult (open circles, $n=24)$ Spratelloides gracilis captured by light traps in the Dampier Archipelago, Western Australia, in November and December 1998. Error bars represents \pm standard errors. 
Fig. 5. Mean size at age $0,5,10,15,20 \mathrm{~d}(\mathrm{~A})$ and mean growth rate at 0-5, 5-10, 10-15, 15-20 and 0-20d age intervals (B) of cohorts of Spratelloides gracilis captured by light traps in summers 1998/1999 and 1999/2000 in the Dampier Archipelago, Western Australia. Samples of juveniles and adults from the same cohort collected in successive months were pooled except for November 1998 where size-selective mortality was detected. Size-at-age and growth rate of these 7 pooled samples of fish are respectively compared by RM MANOVA (factor Age x pooled sample) followed by contrasts analysis. Different letters indicate significant differences at $5 \%$ with smaller letters being for smaller values. Error bars represents $\pm 95 \%$ confidence intervals.

Fig. 6. Correlation between mean seawater temperature during month of hatching and mean size at age $0,5,10,15,20 \mathrm{~d}(\mathrm{~A})$ and mean growth rate at $0-5,5-10,10-15$, 15-20 and 0-20d age intervals (B), respectively, of cohorts of Spratelloides gracilis captured by light traps in summers 1998/1999 and 1999/2000 in the Dampier Archipelago, Western Australia. Samples of juveniles and adults from the same cohort collected in successive months were pooled except for November 1998 where size-selective mortality was detected. Regression lines are shown only to aid visual interpretation of trends. 


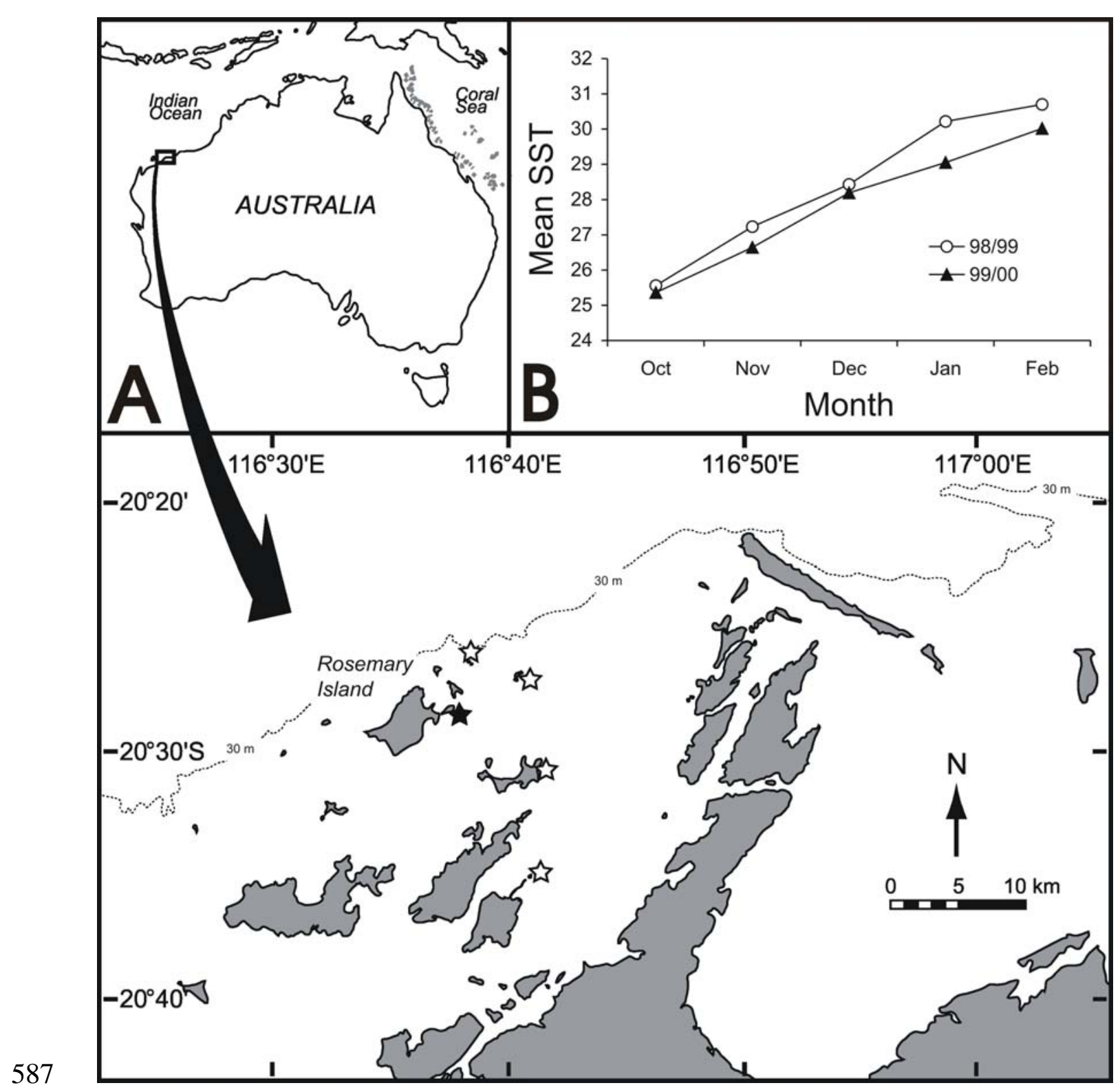

588 Fig. 1. 


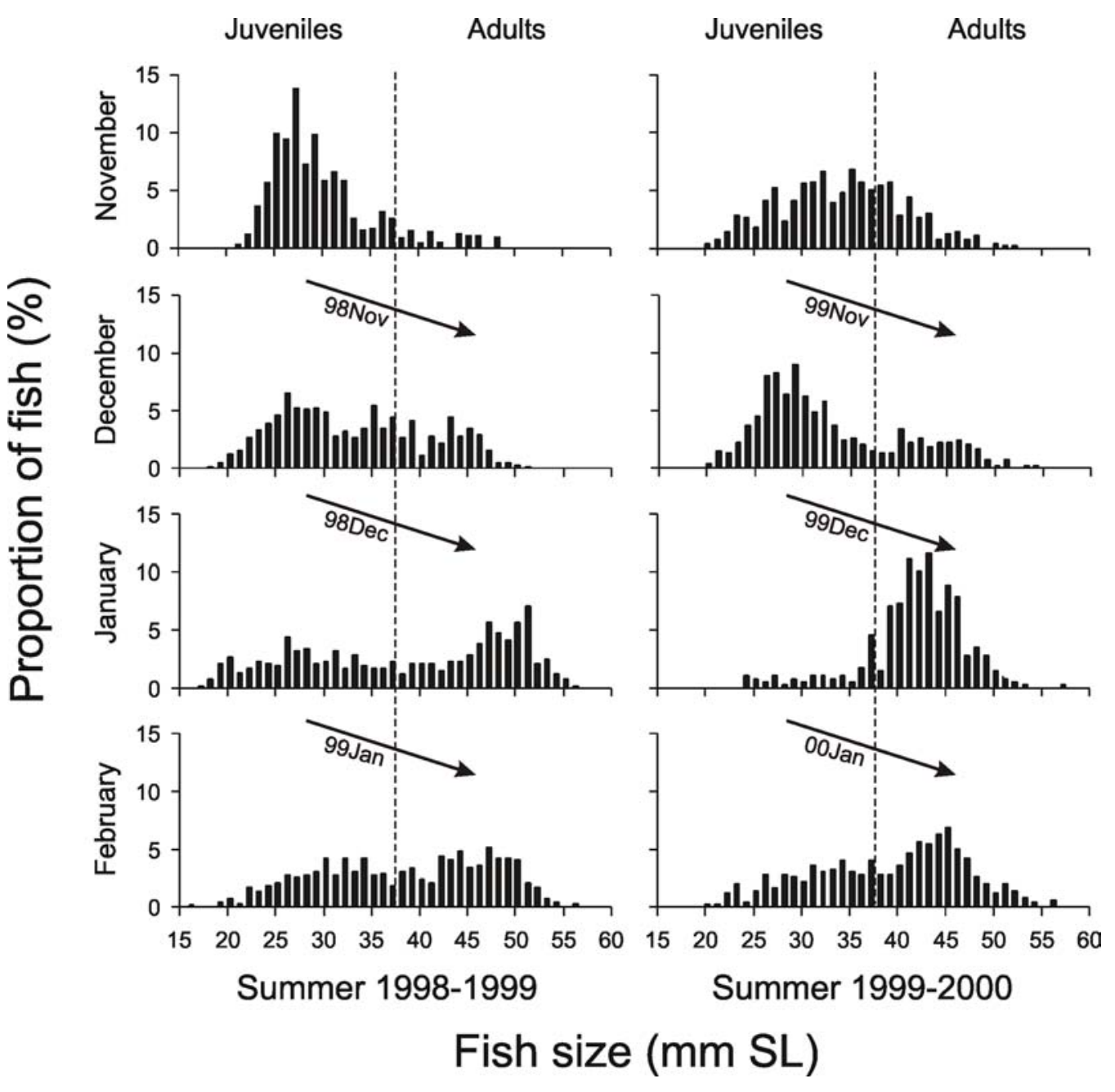

$590 \quad$ Fig. 2. 


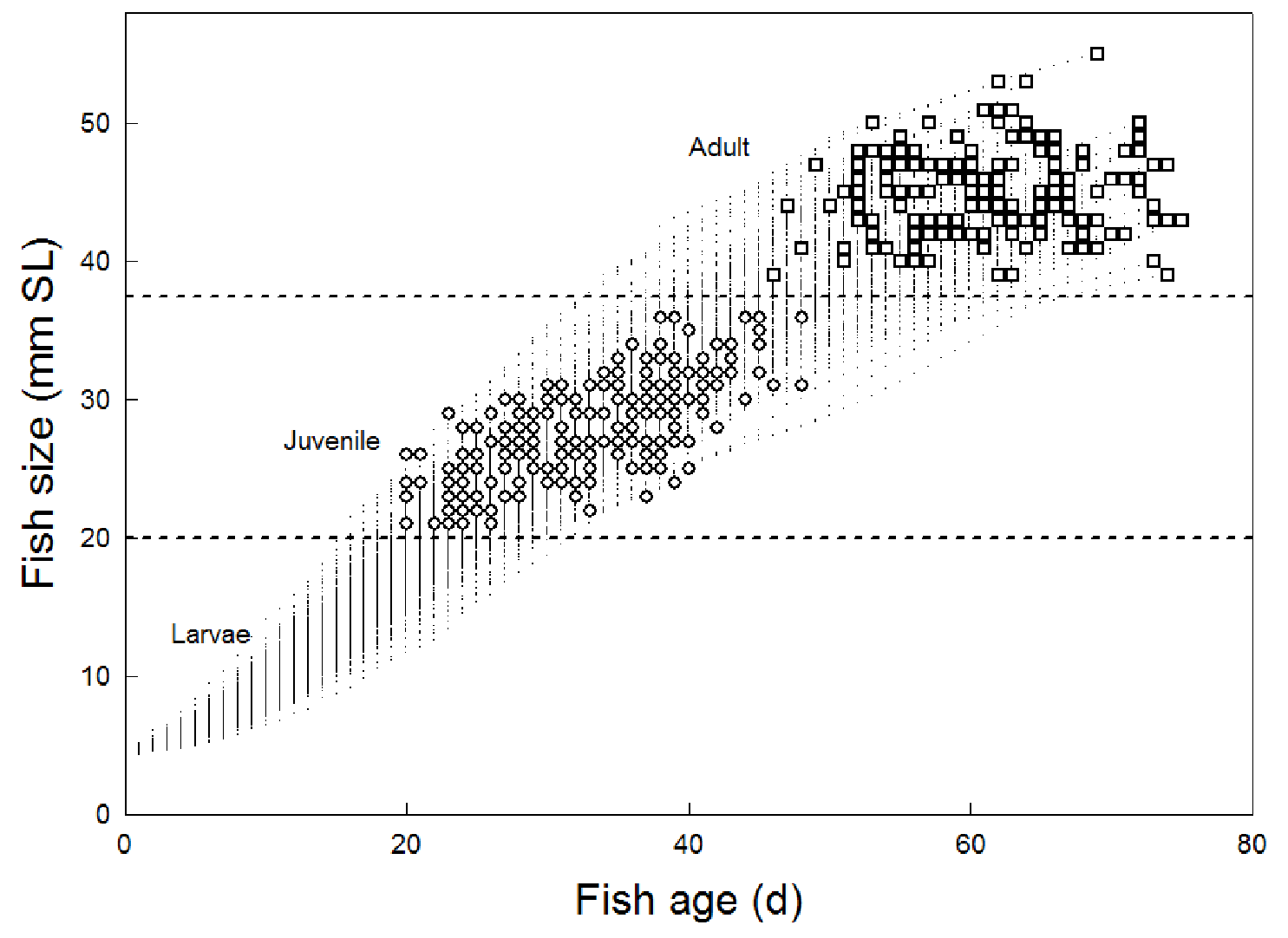

591

592 Fig. 3.

593 

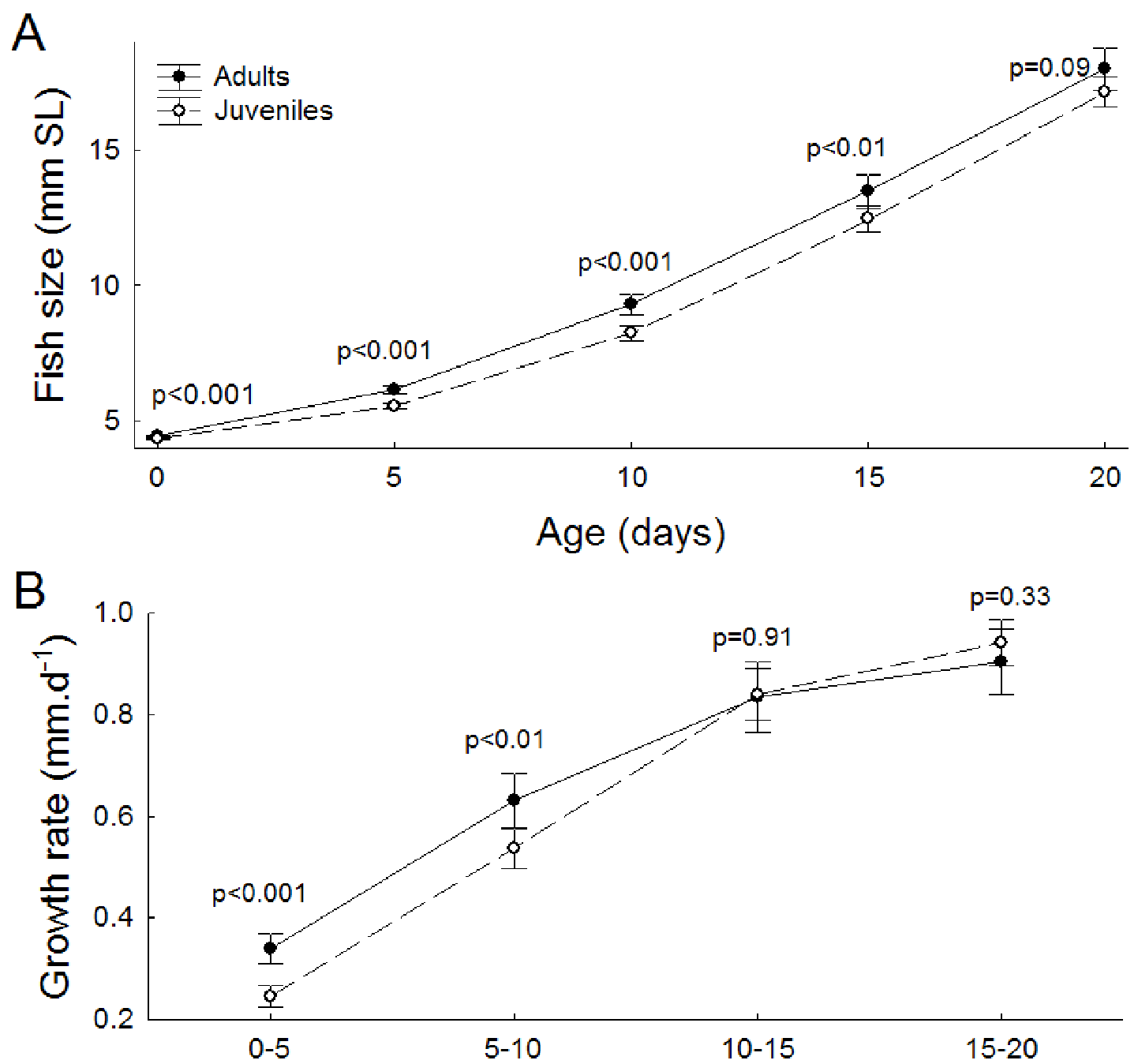

Age interval (days)

593

594 Fig. 4.

595 


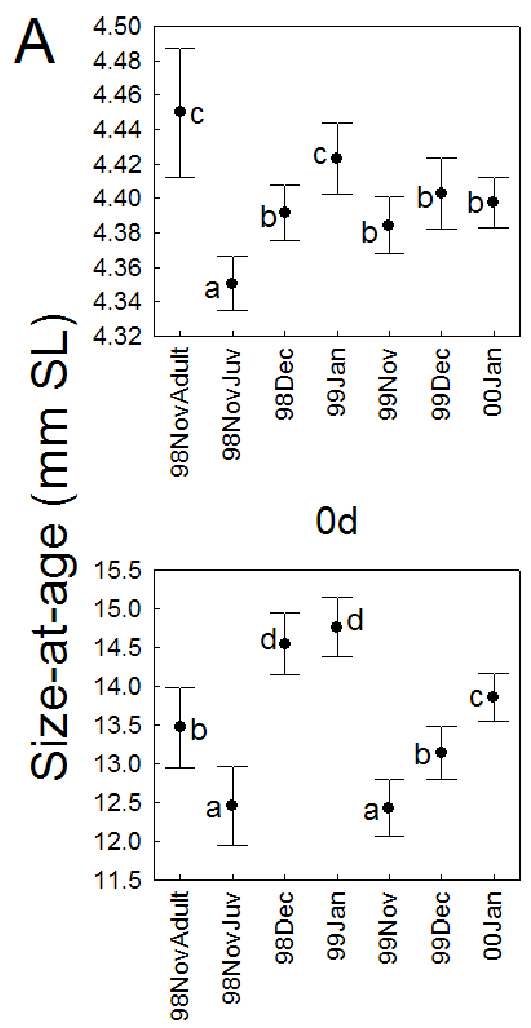

595

596

$15 d$

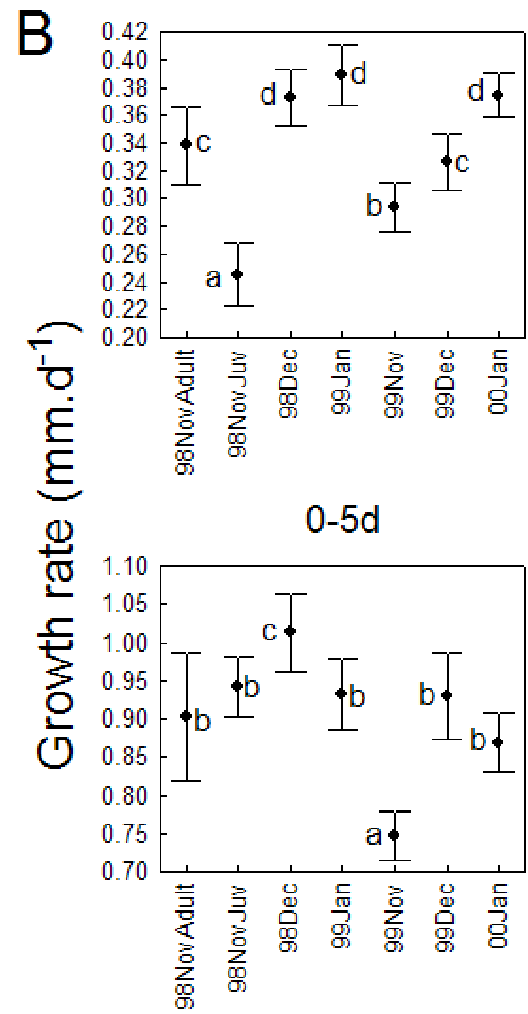

15-20d

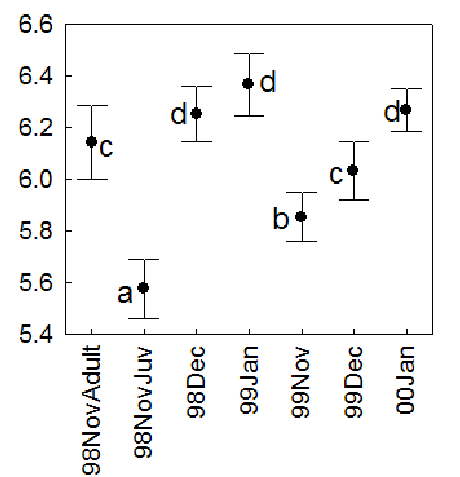

$5 d$

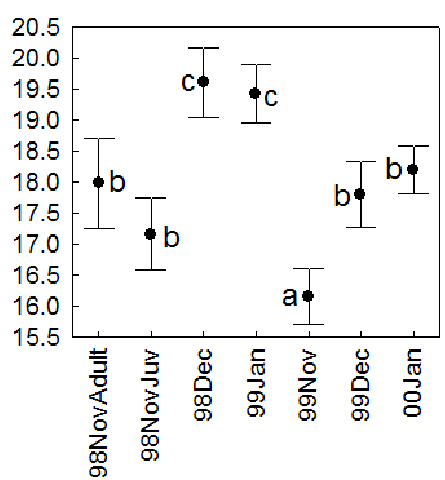

20d

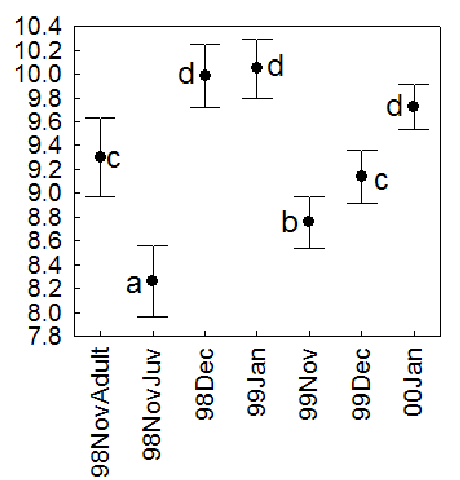

10d

- Mean

工 Mean \pm 0.95 Conf. Interval

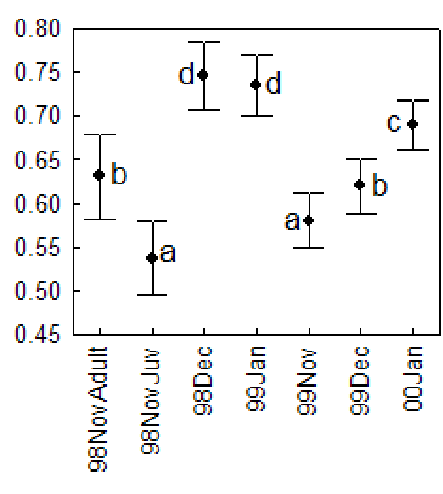

5-10d

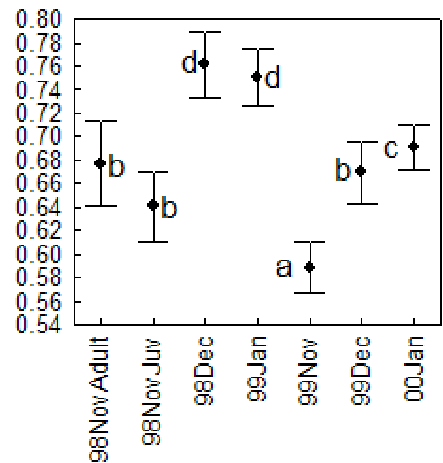

0-20d

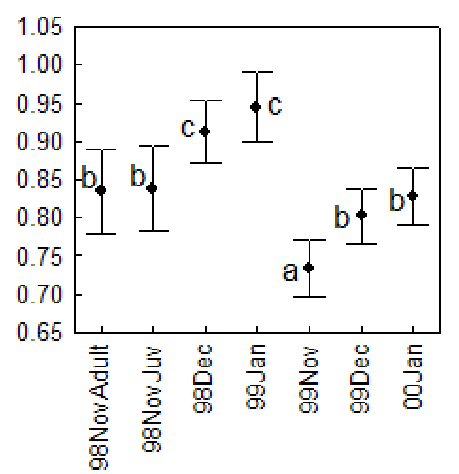

$10-15 d$

- Mean

I Mean \pm 0.95 Conf. Interval

597 Fig. 5. 

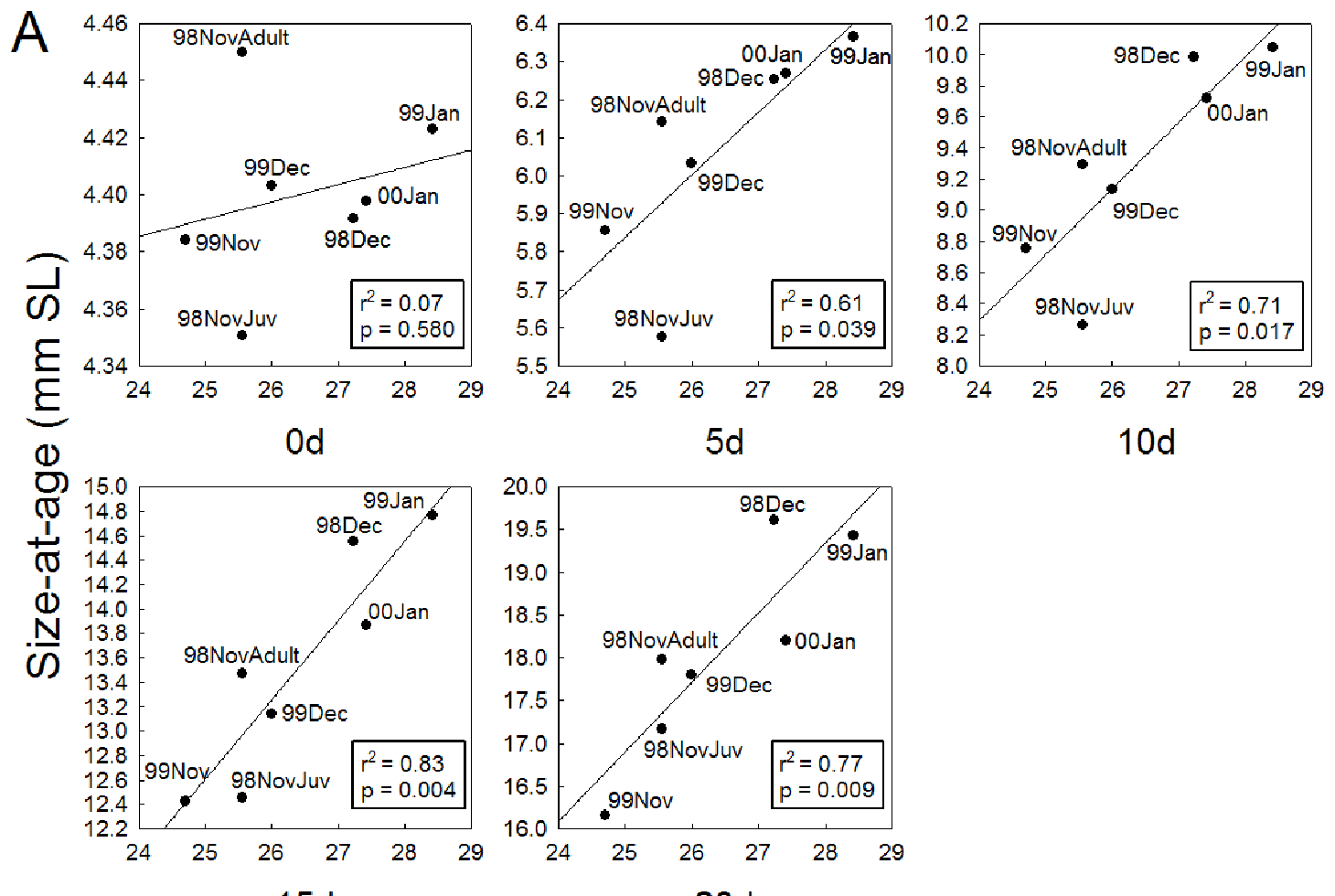

$15 d$

20d

598

599
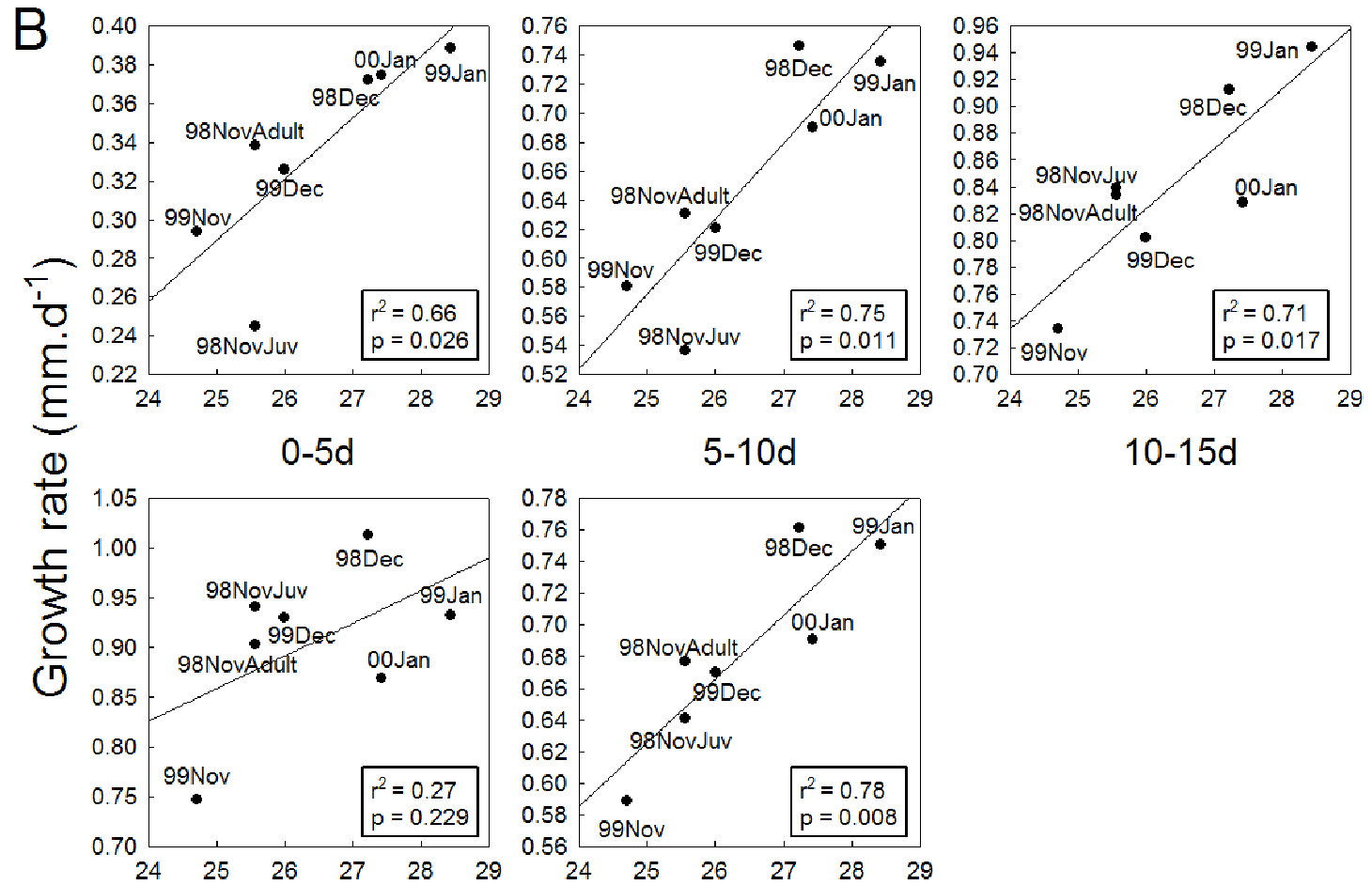

$5-10 d$

$10-15 d$

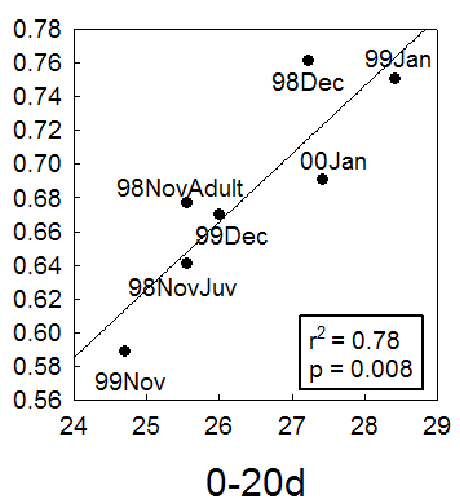

Sea surface temperature during month of hatching $\left({ }^{\circ} \mathrm{C}\right)$

600 Fig. 6. 